\title{
Survey on major micro vascular complication of Diabetes Mellitus Type 1 (T1DM) patients in different age groups in Hyderabad and Jamshoro
}

\author{
Fahmida Channa ${ }^{1}$, Tahira Jabeen Ursani ${ }^{1}$, Jawaid Ahmed Khokhar ${ }^{1 *}$, \\ Samina Malik ${ }^{1}$, Syed Akbar Ali Shah ${ }^{2}$ and Aftab Khaskheli ${ }^{2}$ \\ 1. Department of Zoology, University of Sindh, Jamshoro- 76080-Pakistan \\ 2. Institute of Biotechnology and Genetic Engineering, University of Sindh, Jamshoro-Pakistan \\ *Corresponding author's email: jawaid.khokhar@usindh.edu.pk
}

Citation

Tahira Jabeen Ursani, Fahmida Channa, Jawaid Ahmed Khokhar, Samina Malik, Syed Akbar Ali Shah and Aftab Khaskheli. Survey on major micro vascular complication of Diabetes Mellitus Type 1 (T1DM) patients in different age groups in Hyderabad and Jamshoro. Pure and Applied Biology. Vol. 9, Issue 1, pp1130-1136.

http://dx.doi.org/10.19045/bspab.2020.90118

Received: 10/10/2019 Revised: 27/12/2019

Accepted: $13 / 01 / 2020$

Online First: 30/01/2020

\section{Abstract}

Diabetes mellitus (DM) is a common medical condition known to have adverse effects on all system of human body. Diabetes mellitus is a big threat towards public health. More than 382 million public suffered from DM in the year 2013. The type 1 diabetes mellitus (T1DM) is a multifactorial autoimmune disease and its susceptibility is recognized by combination of environmental factors and heredity factors. Microvascular complications are specific to diabetes and related to longstanding hyperglycemia. The aim of this study was to evaluate the frequency major microvascular complication of different age group patients with T1DM and was conducted in medical outdoor patient department (OPD) of two main hospitals named as Civil Hospital Hyderabad and Liaquat University of Medical and Health Sciences (LUMHS) Jamshoro from July 2018-December 2018. The results found that out of 410 T1DM patients $250(61 \%)$ were males and $160(39 \%)$ were females were enrolled in the present study. The present study concluded that total 410 Diabetic patients have major microvascular complications included 180 (44\%) diabetic retinopathy (DR) patients, 125 (30.4\%) diabetic nephropathy patients and 105(25.6\%) diabetic neuropathy patients. Out of 180 patient $120(66.66 \%)$ males have DR and 60 (33.33\%) females were DR. Out of 125 diabetic nephropathy patients 70 males $(56 \%)$ were suffer and 55(44\%) females. Out of 105 diabetic neuropathic patients, $60(57 \%)$ males and $45(43 \%)$ were females. Out of 180 DR patients, $117(65 \%)$ patients have Non-Proliferative_Diabetic Retinopathy (NPDR) \& 63(35\%) have Proliferative Diabetic Retinopathy (PDR). Out of 125 Diabetic Neuropathy (DN) patients 110 patients have proteinuria, 90 patients have swelling of hands, feet \& ankle, 95 patients have swelling on eyes \& 80 patients have confusion or difficulty to concentrate on work. Out of 105 Diabetic neuropathy patients 100 have numbness, 95 have muscles weakness, 90 have constipation sometimes diarrhea, 65 have urinary incontinence. Out of the total T1DM patients, mostly $320(78 \%)$ of the patients were with uncontrolled glycemic level in the T1DM patient whereas only 90 (22\%) T1DM patients showed glycemic control.

Keywords: Diabetes; Micro vascular Complications; Nephropathy; Neuropathy; Retinopathy 


\section{Introduction}

Diabetes mellitus (DM) is known as huge public health disorders in most of the countries, with about 70 million people are suffering from diabetes mellitus with the change in their living style $[1,2]$. DM is long term metabolic disease of hydrated carbon metabolism due to the lack of insulin production and that leads to hyperglycemia and glycosuria at any stage of human life mostly in childhood $[3,4]$. However, T1DM is autoimmune disorder and is susceptible by both environmental and genetic characteristics [5]. DM is major long-term endocrine metabolic disorder known to have adverse effects on the overall human body. High blood glucose levels can result in brain dysfunction and it promotes the formation of sorbitol, which damages blood vessels and causes degeneration of the nerves, leading to neuropathy, which can lead to dementia [6]. The time period and severity of hyperglycemia develops risk factors for increase in diabetic retinopathy or other micro vascular complications such as nephropathy, retinopathy, and neuropathy [7]. Diabetic retinopathy is considered as one of the common micro vascular complication and responsible for 10,000 blindness cases in each year of the United States [8]. Diabetic retinopathy is notified by high vascular permeability, vascular closure of new blood vessels on the retina and posterior layer of the vitreous and it may be recognized in both type 1 and type 2 diabetic patients. Moreover, DR may be categorized into non-proliferative diabetic retinopathy and proliferative diabetic retinopathy [9].

Diabetic Nephropathy is also the most serious threat in which kidneys fail in their functions such as high blood sugar level [10]. In the first phases of nephropathy diet and drugs may control its condition. The most common kidney failure symptoms are tiredness, loss of appetite, and anemia too $[11,12]$. About 30 to $40 \%$ of Type I diabetics and 20 to $30 \%$ of Type 2 diabetics are found with severe kidney failure.

Diabetic neuropathy is also one of the chronic micro vascular diseases, damaging both somatic and autonomic peripheral nerves [13, 14] and may be characterized as dysfunction of peripheral nerves after the exclusion of other causes of neuropathy. Generally it starts with foot nerves and this condition is known as diabetic peripheral neuropathy (DPN) [15]. Lack of perspiration, feeling of burning and weakness etc are clinical features of diabetic neuropathy [16].

Keeping in view the importance of T1DM as serious disorder, the present research work was designed to document age wise patients suffering from major micro vascular complications (MVCs) of T1DM from two different district hospitals of Sindh-Pakistan.

\section{Materials and methods}

During the regular visits of OPD at two major hospitals named Civil Hospital, Hyderabad and LUMHS, Jamshoro were conducted to collect primary data from July to December 2018. Data were collected through selfdeveloped Questionnaire in English version (Table.1). During visit oral consent was taken from the type 1 Diabetes Mellitus (T1DM) patients and predesigned questionnaire regarding the T1DM is being filled out by asking questions to the medical OPD patients of both hospitals. In total 410 major micro vascular complication of T1DM, patients of different sex age groups were surveyed from both of the above-mentioned hospitals from July to December 2018. Among those 410 patients (250 males and 160 females) were included for thorough medical history, especially taking into account the duration of illness, chronic complications previous blood sugar records, dietary control and treatment record of the patients were taken. Blood pressure and random blood glucose readings for Diabetic patients (type-1) were recorded. Moreover, Oral consent was also taken from all the Diabetic patients. Patients with 
different ages of both sexes were also recorded with their controlled or uncontrolled diabetics based on blood glucose measurements either random or fasting. Questionnaire related to age group of the patients were designed and graphically represented by using "www.GraphPad Prism for Windows version. Statistical significance was determined by using Statistical Package for the Social Sciences (SPSS) tool to determine the significant effects. In addition, differences in the means of different variables between the age and hospital groups were tested using the t-test.

Table 1. Questionnaire about Microvascular complications of Type1 Diabetes patients used in the present study

\begin{tabular}{|c|c|c|c|}
\hline $\begin{array}{c}\text { S. } \\
\text { No. }\end{array}$ & Questionnaire & Yes & No \\
\hline 01 & Do you known about T1DM? & & \\
\hline 02 & Do you known about symptoms and complication of T1DM? & & \\
\hline 03 & Do you known about symptom of heart attack? & & \\
\hline 04 & Do you known about symptom of stroke? & & \\
\hline 05 & Is in your family any one suffer from T1DM? & & \\
\hline 06 & Did your eye sight decreased sudden of gradually? & & \\
\hline 07 & Vision affected on both eyes and only one eye? & & \\
\hline 08 & Do you have persistent pain or sometime? & & \\
\hline 09 & Do you feel swelling of feet \& ankle? & & \\
\hline 10 & Are you using your proper diabetic diet plan? & & \\
\hline 11 & Are you maintaining your body weight? & & \\
\hline 12 & Do you have persistent itching? & & \\
\hline 13 & Do you have pain \& numbness of lower leg? & & \\
\hline 14 & Do you exercise and walk easily or feel pain \& swelling of feet? & & \\
\hline
\end{tabular}

\section{Results}

The present study describes the analysis of the main variables surveyed in the survey questionnaire. Out of 410 T1DM patients (Table 2) of both gender of two different age groups (20-25 \& 26-30 years) were surveyed during the study (Table 3 ). Out of 410 T1DM patients $250(61 \%)$ were males and 160 (39\%) were females were enrolled in the present study. The present study concluded that total 410 Diabetic patients have major microvascular complications included 180 (44\%) DR patients, 125 (30.4\%) nephropathy patients and neuropathy patients $105(25.6 \%)$ (Table 4).Out of 180 patients $120(66.66 \%)$ males have DR and 60 (33.33\%) females were DR (Table 5). Out of 180 DR patients $117(65 \%)$ patients have NPDR \& $63(35 \%)$ have PDR (Table 6). Out of 180 DR patents $125(69.45 \%)$ patients vision loss gradually \& $55(30.55 \%)$ patients vision loss suddenly .Out of 125 diabetic nephropathy patients 70 
males (56\%) were suffer and $55(44 \%)$ females (Table 7). The symptoms found in the diabetic patients which were 125 , all have proteinura as a major symptom, in 110 patients the swelling of feet and hand was noticed, 95 patients of diabetic nephropathy showed eyes swelling and 80 diabetic nephropathy patients showed confusion or difficulty in concentration (Table 8 \& 9). Total 105 diabetic neuropathic patients 60 (57\%) males and 45 (43\%) females (Table $10)$.

Table 2. Showing Diabetic Mellitus type 1 patients attending the medical OPD of Civil Hospital Hyderabad and LUMHS Jamshoro $(n=410)$

\begin{tabular}{|c|c|c|}
\hline Gender & Number of T1DM Patients & \% \\
\hline Male & 250 & $61 \%$ \\
\hline Female & 160 & $39 \%$ \\
\hline
\end{tabular}

Table 3. Showing the age of Type 1diabetes mellitus (T1DM) patients $(n=410)$

\begin{tabular}{|c|c|c|}
\hline Age group & NO: of patients & Percentage (\%) \\
\hline $26-30$ & 249 & $60.73 \%$ \\
\hline $20-25$ & 161 & $39.2 \%$ \\
\hline
\end{tabular}

Table 4. Showing Diabetic Mellitus type 1(T1DM) patients attending the medical OPD of Civil Hospital Hyderabad and LUMHS Jamshoro having microvascular complication $(n=410)$

\begin{tabular}{|c|c|}
\hline Major micro vascular complication in T1DM patients & No. of patients \\
\hline Diabetic retinopathy & 180 \\
\hline Diabetic nephropathy & 125 \\
\hline Diabetic neuropathy & 105 \\
\hline
\end{tabular}

Table 5. Showing gender with percentage of Diabetic retinopathy (DR) patients

\begin{tabular}{|c|c|c|}
\hline Gender & Numbers of DR Patients & Percentage (\%) \\
\hline Male & 120 & 66.66 \\
\hline Female & 60 & 33.33 \\
\hline
\end{tabular}

Table 6. Showing type wise number $\& \%$ of DR patients $(n=180)$

\begin{tabular}{|c|c|c|}
\hline Type of DR & Numbers & Percentage \\
\hline NPDR & 117 & $65 \%$ \\
\hline PDR & 63 & $35 \%$ \\
\hline
\end{tabular}

Table 7. Showing gender with percentage of Diabetic nephropathy (DN) patients

\begin{tabular}{|c|c|c|}
\hline Gender & Numbers of DN patients & Percentage (\%) \\
\hline Male & 70 & 56 \\
\hline Female & 55 & 44 \\
\hline
\end{tabular}


Table 8. Showing Diabetic Nephropathy patients symptoms $(n=125)$

\begin{tabular}{|c|c|}
\hline Symptoms & No. of patients \\
\hline Proteinuria & 125 \\
\hline Swelling of feet, ankle \& hands & 110 \\
\hline Swelling of eyes & 95 \\
\hline Confusion or difficulty concentrating & 80 \\
\hline
\end{tabular}

Table 9. Showing Diabetic Nephropathy patients symptoms $(n=125)$

\begin{tabular}{|c|c|c|}
\hline Symptoms & No. of patients & \% \\
\hline Proteinuria & 125 & $100 \%$ \\
\hline Swelling of feet, ankle \& hands & 110 & $80 \%$ \\
\hline Swelling of eyes & 95 & $76 \%$ \\
\hline Confusion or difficulty concentrating & 80 & $64 \%$ \\
\hline
\end{tabular}

Table 10. Showing gender with percentage of Diabetic neuropathy patients

\begin{tabular}{|c|c|c|}
\hline Gender & Numbers of diabetic neuropathy patients & Percentage (\%) \\
\hline Male & 60 & 57 \\
\hline Female & 45 & 43 \\
\hline
\end{tabular}

\section{Discussion}

The present study was carried out to determine the prevalence of major micro vascular complications of T1DM in both male and female of different ages between (20-25 and 26-30) years at two major hospitals of Sindh-Pakistan during July to December 2018. DM is multifactorial disorder leads to increase glucose in the blood because of impairment of insulin secretion and function, insulin function, or both. DM commonly developed at the age of forty. DM is major long term endocrine disease known to have adverse effects on the overall human body. High blood glucose levels can result in brain dysfunction and it promotes the formation of sorbitol, which damages blood vessels and causes degeneration of the nerves, leading to neuropathy which can lead to dementia [6]. The present study was based on survey and used routinely collected data through questionnaire by asking the questions from a defined population at a certain specific period of time in the local language which was then after converted into English language. These data were then examined in relation to the presence or absence of the diabetes disease under investigation or its severity with a view to test hypothesis and look into associations between various factors. Studies was planned to carry the survey in the district Hyderabad of Sindh Province to find out the number of persons in both genders having of major micro vascular complication of T1DM. According to Kaplan-Meier estimates, by 3 years after DM diagnosis, at least $18.0 \%$ of youths with T1DM developed DR KaplanMeier .et al. previous studies reporting sexrelated differences in the development of DR have been only in youths with T1DM and have been inconsistent, noting either increased DR among female patients [17-19] postulating hormonal differences during maturity as a possible explanatory factor. Increasing risk of DR among patients who were diagnosed with T1DM at older ages has also been reported previously and postulated to be associated to increased risk related with maturity [20]. Concordance of diabetic 
nephropathy and DR could be due to common risk factors or could be a marker of general vascular damage, leading to leakage of protein from eye vessels [21].

\section{Conclusion}

The present study concluded that total 410 Diabetic patients have major microvascular complications included 180 (44\%) DR patients, $125(30.4 \%)$ nephropathy patients and neuropathy patients $105(25.6 \%)$.Out of 180 patients $120(66.66 \%)$ males have DR and $60(33.33 \%)$ females were DR. Out of 125 diabetic nephropathy patients 70 males $(56 \%)$ were suffer and 55 (44\%) females. Out of 105 diabetic neuropathic patients $60(57 \%)$ males and 45 (43\%) females.

\section{Authors' contributions}

Conceived and designed the experiments: TJ Ursani \& J Ahmed, Performed the experiments: F Channa, Analyzed the data: T Jabeen \& J Ahmed, Contributed materials/ analysis/ tools: F Channa, TJ Ursani, Wrote the paper: Ahmed, SAA Shah \& A Khaskheli.

\section{References}

1. David SK, Upadhayaya N, Siddiqui MK \& Usmani AM (2010) Knowledge Discovery Technique for Web-Based Diabetes Educational System. J Health Med Informat 1: 102.

2. Zimmet P, Alberti KG \& Shaw J (2001) Global and societal implications of the diabetes epidemic. Nature 414: 782-787.

3. Ramanathan K, Karthick H \& Arun N (2010) Structure Based Drug Designing for Diabetes Mellitus. J Proteomics Bioinform 3: 310-313.

4. Baş VN, Bideci A, Yeşilkaya E, Soysal AS \& Çamurdan O et al. (2011) Evaluation of Factors Affecting Quality of Life in Children with Type 1Diabetes Mellitus. J Diabetes Metab 2: 154.

5. Ribeiro $\mathrm{C}$, de Alencar Mota CS, Voltarelli FA, de Araújo MB \& Botezelli JD et al. (2010) Effects of Moderate
Intensity Physical Training in Neonatal Alloxan- Administered Rats. J D6.

6. Alina S, Barbara R, Krzysztof G, Barbara G \& Marek G et al. (2011) Elevation of sE-Selectin Levels from 224 Months Following Gestational Diabetes is Associated with Early Cardiometabolic Risk in Non-Diabetic Women. J Diabetes Metab 2: 138.

7. Brownlee M (2001) Biochemistry and molecular cell biology of diabetic complications. Nature 414: 813-820.

8. Kodl CT \& Seaquist ER (2008). Cognitive dysfunction and scope diabetes mellitus. Endocr Rev 29:494511.

9. Silva SB, Costa JP, Pintado ME, Ferreira DC \& Sarmento B (2010) Antioxidants in the Prevention and Treatment of Diabetic Retinopathy - A Review. J Diabetes Metab 1: 111-146.

10. Chowdhury TA, Dyer PH, Kumar S, Barnett AH \&Bain SC (1999) Genetic determinants of diabetic nephropathy. Clin Sci (Lond) 96: 221-230.

11. Rossing P (2000) Risk factors in the progression of diabetic nephropathies. Ugeskr Laeger 162: 5057-5061.

12. Lehmann $\mathrm{R} \&$ Spinas GA (1995) Diabetic nephropathy: significance of microalbuminuria and proteinuria in Type I and Type II diabetes mellitus. Praxis (Bern 1994) 84: 1265-1271.

13. Thomas M, Tsalamandris $\mathrm{C}$, MacIsaac $\mathrm{R}$ \& Jerums G (2005) Anaemia in diabetes: an emerging complication of microvascular disease. Curr Diabetes Rev 1: 107-126.

14. Chen D, Huang H, Xing Y, Liu Y \& Xu $Y$ et al. (2011) A New Vanadium Complex Improves the Spatial Learning and Memory by Activation of Caveolin- 
MAPK-CREB in pathway diabetic Mice. J Diabetes Metab 2: 114.

15. Heltianu C \& Guja C (2011) Role of Nitric Oxide Synthase Family in Diabetic Neuropathy. J Diabetes Metab S5: 2. 55. Boulton AJ (1994) End-stage complications of diabetic neuropathy: foot ulceration. Can J Neurol Sci 21: S18-22.

16. Boulton AJ (1994) End-stage complications of diabetic neuropathy: foot ulceration. Can J Neurol Sci 21: S18-22.

17. Minuto N, Emmanuele V \& Vannati M et al. (2012). Retinopathy screening in patients with type 1 diabetes diagnosed in young age using a non-mydriatic digital stereoscopic retinal imaging. $J$ Endocrinol Invest 35: 389-394.

18. Benitez-Aguirre P, Craig ME, Cass HG et al. (2014). Sex Differences in retinal microvasculature through puberty in type 1 diabetes: are girls at greater risk of diabetic microvascular complications. Invest Ophthalmol Vis Sci 56: 571-577.

19. Harjutsalo V, Maric C, Forsblom C et al. (2011). Sex-related differences in the long-term risk of microvascular complications by age at onset of type 1 diabetes. Diabetologia 54: 1992- 1999.

20. Forga L, Goñi MJ \& Ibáñez B et al. (2016). Influence of age at diagnosis and time-dependent risk factors on the development of diabetic retinopathy in patients with type 1 diabetes. $J$ of Diabetes Res 1-7. Article ID 9898309.

21. Ciulla TA, Amador AG \& Zinman B (2003). Diabetic retinopathy and diabetic macular edema: pathophysiology, screening, and novel therapies. Diabetes Care 26: 2653-2664. 